\title{
South Pole glacial climate reconstruction from multi-borehole laser particulate stratigraphy
}

\author{
The IceCube Collaboration* \\ *For full author list, see Appendix
}

\begin{abstract}
The IceCube Neutrino Observatory and its prototype, AMANDA, were built in South Pole ice, using powerful hot-water drills to cleanly bore $>100$ holes to depths up to $2500 \mathrm{~m}$. The construction of these particle physics detectors provided a unique opportunity to examine the deep ice sheet using a variety of novel techniques. We made high-resolution particulate profiles with a laser dust logger in eight of the boreholes during detector commissioning between 2004 and 2010. The South Pole laser logs are among the most clearly resolved measurements of Antarctic dust strata during the last glacial period and can be used to reconstruct paleoclimate records in exceptional detail. Here we use manual and algorithmic matching to synthesize our South Pole measurements with ice-core and logging data from Dome C, East Antarctica. We derive impurity concentration, precision chronology, annual-layer thickness, local spatial variability, and identify several widespread volcanic ash depositions useful for dating. We also examine the interval around $\sim 74 \mathrm{ka}$ recently isolated with radiometric dating to bracket the Toba (Sumatra) supereruption.
\end{abstract}

\section{INTRODUCTION}

More than 50 years ago, Markov and Zheleznykh proposed using gigatons of transparent material underground as a detector of cosmic neutrinos (see Markov and Zheleznykh, 1986, and references therein). The IceCube Neutrino Observatory completed in December 2010 (IceCube Collaboration, 2006) and its predecessor, AMANDA (Antarctic Muon and Neutrino Detector Array; AMANDA Collaboration, 2001), have applied this concept in the deep ice at the South Pole to study fundamental questions in physics and astrophysics. These telescopes use large volumes of ice to observe the subatomic charged particles produced by energetic neutrinos, that have fortuitously interacted via the weak force with nucleons in the ice near the detector. Muons, hadronic cascades and electromagnetic cascades generated by the neutrinos can be tracked via chargedparticle Cherenkov radiation at ultraviolet and visible wavelengths with an embedded matrix of sensitive photomultipliers. The density of sensors and size of the instrumented volume determine the threshold, resolution and practicably attainable upper limit of detected neutrino energies. Since the spectrum of cosmic neutrinos is presumed to roughly follow that of cosmic rays and fall steeply with energy, IceCube was designed at the kilometer scale to detect small fluxes of neutrinos in the $1 \mathrm{TeV}$ to $1 \mathrm{PeV}$ energy range over the lifetime of the experiment.

The buried component of IceCube consists of 5160 photomultiplier tubes, frozen into 86 boreholes and arrayed over $1 \mathrm{~km}^{3}$ from $1450 \mathrm{~m}$ to $2450 \mathrm{~m}$ depth (IceCube Collaboration, 2009). IceCube and AMANDA rely on the extreme clarity of Antarctic ice, at sufficient depths that all residual air bubbles originally trapped in surface snow have converted to hydrates. Air clathrate hydrate crystals have almost exactly the same refractive index as ice $\left(\Delta n / n \approx 4 \times 10^{-3}\right.$; Uchida and others, 1995) and so are essentially transparent. The first detector, AMANDA-A deployed in 1994, was installed at depths between 800 and $1000 \mathrm{~m}$ in the expectation that all bubbles had converted at those depths. Barkov and Lipenkov had carried out a painstaking analysis of fresh Vostok ice-core samples, crucially, within a few weeks of coring and before the hydrates could revert back to air bubbles upon relaxation at the surface. Their work (Barkov and Lipenkov, 1985) presaged our discovery that South Pole ice is still bubbly at depths shallower than $1300 \mathrm{~m}$. Bubble scattering prevented accurate directional reconstruction, and AMANDAA was mainly effective as a subatomic particle calorimeter (Askebjer and others, 1995) but not as a telescope. Bubbles decrease in size with depth but persist until at least $\sim 1350 \mathrm{~m}$ at South Pole, and to comparable or greater depths at every location we have studied in the interiors of Antarctica and Greenland.

IceCube construction depended critically on the drilling team and the $5 \mathrm{MW}$ Enhanced Hot-Water Drill (EHWD), capable of boring 20 holes, each $2500 \mathrm{~m}$ deep and $60 \mathrm{~cm}$ in diameter, in a 2 month season. This massive ice-drilling project has enabled us to investigate South Pole ice and create synergies with other disciplines. Our studies to date include precision measurements of optical properties (Woschnagg and Price, 2001; Ackermann and others, 2006; IceCube Collaboration, 2013); acoustic properties (IceCube Collaboration, 2010, 2011); glaciological properties such as flow, shear and temperature (Price and others, 2002); and paleoclimatology, including a reconstruction of surface roughness as a proxy for cyclonic activity (Bay and others, 2010).

A principal aspect of calibrating the IceCube detector has been to map scattering and absorption of light in the deep ice. Bubble-free Antarctic ice is the purest natural solid on Earth, and the most transparent at ultraviolet to visible wavelengths. Photons with wavelengths shorter than $\sim 200 \mathrm{~nm}$ are strongly attenuated by electronic absorption in water; for wavelengths longer than $\sim 600 \mathrm{~nm}$, molecular absorption dominates. Between 200 and $600 \mathrm{~nm}$, transmission in ice is limited by trace impurities (He and Price, 1998). To model the response of the detector, we must account for impurity variations in three dimensions, particularly due to climatic and glaciological changes in continental mineral 
dust and volcanic ash inclusions with depth (Ackermann and others, 2006; IceCube Collaboration, 2013). The concentration and character of deposited particulates in the ice vary due to glacial flow and past climate changes, with higher concentrations corresponding to periods of greater abundance of dust available from source regions, and possibly longer-range transport due to changes in atmospheric circulation or precipitation (Legrand and Mayewski, 1997; Li and others, 2010). The mineral dust found in Antarctic ice is thought to originate primarily in Patagonia, with uncertain and possibly variable contributions from Australia, New Zealand and Africa (Delmonte and others, 2008; Li and others, 2008; Gabrielli and others, 2010). The ice in which IceCube is instrumented accumulated during the last glacial period, with climate changes manifest as variations in optical clarity of nearly an order of magnitude. Bulk absorption length ranges from 30 to $>200 \mathrm{~m}$, in ice from colder versus warmer periods respectively. Effective scattering length varies between about 5 and $70 \mathrm{~m}$. Volcanic ash layers, particularly those deposited by local circum-Antarctic volcanoes, can severely degrade optical transparency on the centimeter scale.

AMANDA and IceCube used various light sources embedded in the ice with the detector to make optical measurements at $\sim 10 \mathrm{~m}$ resolution (Ackermann and others, 2007; IceCube Collaboration, 2013). In addition, we deployed laser dust loggers (Bramall and others, 2005) in eight IceCube boreholes. The logger can often produce a more stratigraphically coherent environmental record than can be obtained from ice-core measurements, which must make do with mere $\sim 0.001 \mathrm{~m}^{2}$ sections of the horizon. In holes drilled mechanically using non-freezing fluid to retrieve a core, optical logging data can be degraded by scarring of the borehole wall (Bramall and others, 2005; Fudge and Smith, 2010), fluid contamination and refractive mismatch with the ice. The IceCube hot water holes, however, provided almost ideal conditions for imaging dust and volcanic particulate horizons at millimeter depth resolution (Bramall and others, 2005).

Here we develop a detailed South Pole climate record by correlating our measurements to the EDC99 ice core taken at Dome C, East Antarctica, by the EPICA Collaboration (European Project for Ice Coring in Antarctica; Parrenin and others, 2007a; Lambert and others, 2012) together with the laser borehole log we made there in January 2010. The South Pole record is unbroken to $100 \mathrm{ka}$ BP at the IceCube location. Extrapolation indicates that South Pole ice should include the Eemian period, the last interglacial $\sim 120 \mathrm{ka} \mathrm{BP}$ with a climate analogous to but several degrees warmer than the present day (Sime and others, 2009). Although the South Pole is one of the most studied locations in Antarctica, no ice core deeper than a few hundred meters has ever been retrieved from the site. Partly based on the AMANDA and IceCube datasets, including results shown here, South Pole has been designated as the site of the next major US icecoring mission.

\section{METHODS}

Optical and photonic logging instruments deployed in glacial boreholes can provide a wealth of information, without retrieval or destruction of core samples. The dust logger (Bay and others, 2001) grew out of years of AMANDA

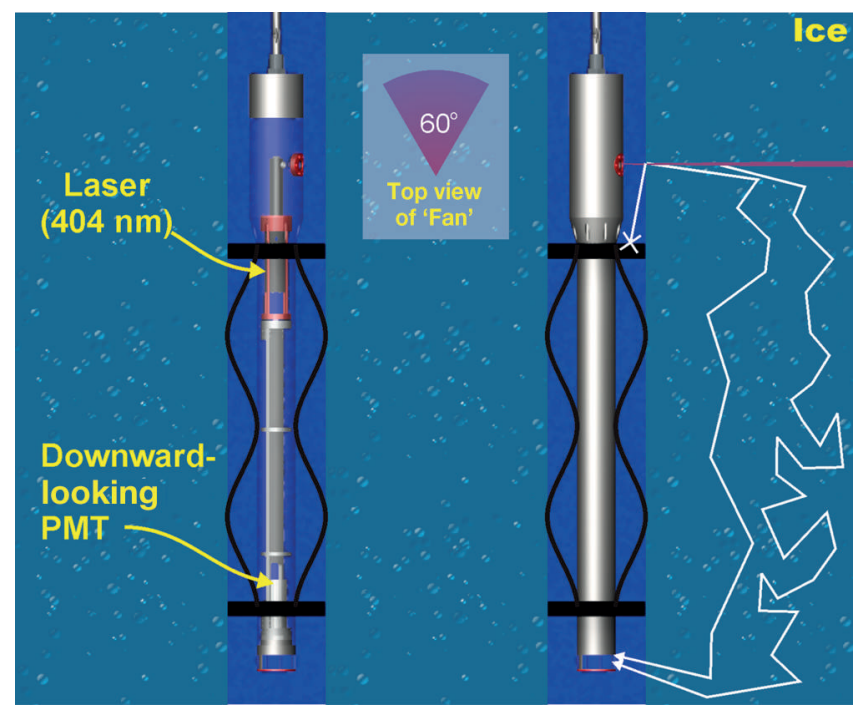

Fig. 1. Ruggedized laser dust logger deployed in IceCube. The $404 \mathrm{~nm}$ diode laser is focused into a fan beam to probe $60^{\circ}$ of the horizon in one pass. Brush baffles block photons which circumvented the ice through the borehole, and clear away detritus in the hole that could obstruct the image. IceCube hot-water boreholes were larger and less uniform than depicted in the diagram.

experience in using emitters and receivers embedded in ice to measure optical properties. The $\sim 1 \mathrm{~m}$-long logger (Fig. 1) shines light into the ice surrounding a borehole; photons scatter off bubbles and impurities to be eventually absorbed; a small fraction $\left(10^{-10}\right.$ to $\left.10^{-6}\right)$ of photons return to be detected. Annular black nylon brush baffles sweep ice crystals and debris from the source beam and intercept stray light, to ensure that all detected photons have exited and reentered the borehole after interacting with the target layer.

The intrinsic depth resolution of the logger is determined by the thickness of the laser line and not the distance of the receiver from the source, which we have confirmed using Monte Carlo simulations (Bay and others, 2001) and other logger geometries we have tested (Bay and others, 2006). The signal is dominated by first encounters of the laser with particulates in the coherence plane of the beam, which probes approximately one effective scattering length into the ice. The further the source beam penetrates horizontally the greater the coherence with the target dust layer, up to the scale of stratigraphic undulations or tilt. At depths where scattering is bubble-dominated, the ice is diffusively illuminated by scattered light and the logger signal tracks impurity levels through absorption, responding markedly to thin volcanic ash layers. In deep clear ice, the backscattering signal is a nearly direct tracer of ash and continental mineral dust.

In 2004 we designed and built a new dust logger for use during IceCube commissioning (Bramall and others, 2005). We improved upon previous designs by using a temperatureregulated diode laser at $404 \mathrm{~nm}$ wavelength near the absorption minimum for glacial ice (Askebjer and others, 1997a), a photon-counting detector (Hamamatsu HC135), onboard computer control (Rabbit RCM3720) and DSL (digital subscriber line, Patton Electronics Co., Gaithersburg, MD, USA) telemetry to the surface.

While more ideal optics could scan an entire $360^{\circ}$ with adjustable azimuthal integration, we compromised on a ruggedized design that could survive many rapid 
redeployments by restricting the focus of the laser plane to span a fixed $60^{\circ}$ of the horizon. The pressure vessel was constructed from hardened stainless steel and synthetic sapphire optical components. The brush baffles extended to 18 in $(\sim 46 \mathrm{~cm})$ in diameter, not enough to completely seal the annulus of the holes, which typically varied from 45 to $75 \mathrm{~cm}$ diameter. Raw photon counts were corrected for pileup at high light levels and normalized to the intensity of the laser. Depth was reconstructed to an absolute accuracy of 1-2 $\mathrm{m}$ from Bourdon tube pressure sensors (Paroscientific, Redmond, WA, USA). The reconstruction incorporated winch payout, surface surveys, well depth measured with a laser rangefinder, and corrections for water column compressibility and cable stretch.

The first two loggers were permanently attached to the bottoms of detector strings and took data as the strings were deployed. Beginning with the 2006/07 season, we used a small winch to deploy and recover the instrument at a nominal logging speed of $\sim 25 \mathrm{~cm} \mathrm{~s}^{-1}$. Each borehole was logged in one $\sim 6$ hour round trip, immediately after drilling, to leave time for installation of the detector string in the refreezing hole.

In January 2010, we deployed the laser dust logger at the EPICA Dome C ice-core (EDC99) site in East Antarctica $\left(75^{\circ} 06^{\prime} \mathrm{S}, 123^{\circ} 21^{\prime} \mathrm{E}\right)$, to obtain the particulate history which dates to 800 ka there (Jouzel and others, 2007). The laser data from the EDC99 borehole were somewhat obscured by turbidity from drill fluid contaminants, but were effective for finding many additional candidate ash layers beyond those previously investigated in the core (Narcisi and others, 2005).

Bigler and others (2006) performed continuous flow analysis (CFA) on melted EDC99 core samples, including laser-absorption particle sensing of total insoluble dust, fluorescence spectroscopy of $\mathrm{Ca}^{2+}$ and absorption spectroscopy of $\mathrm{Na}^{2+}$. Lambert and others (2012) derived a record of Dome $\mathrm{C}$ calcium ions excluding those due to Ca-rich sea salt, i.e. non-sea-salt calcium (nssCa ${ }^{2+}$ ), which is a proxy for continental silicate mineral dust.

Laser borehole logging and core measurements complement other methods for measuring atmospheric particulate variations as preserved in ice. The logging signal is a relative measure of scattering and absorption due to impurities and bubbles. The logger captures high-definition images of the optical effects of particulates averaged over an area of order $\mathrm{m}^{2}$ of the horizon. This method is often less susceptible than a core sample to the depositional noise, redistribution and erosion that degrade continuity of the preserved climate record. The logger signal amplitude can be affected by hole light leakage and a varying distance to the target dust, particularly in the large boreholes of IceCube, and exhibits some smoothing from pre-imaging and post-imaging spillover at depths near strong optical features. Ice-core CFA systems make measurements with millimeter spatial resolution, which is well below the scale of homogeneity of the cores. Core samples comprise only a few $\mathrm{cm}^{2}$ area of the horizon, and measurements need to be averaged over a finite depth interval to meaningfully represent the stratigraphic record. Core records may miss thin deposition events and contain gaps, depth registration errors, intersample mixing and particle loss intrinsic to CFA.

By identifying common features precisely, we can synchronize our laser profiles and combine them into a full-resolution average South Pole particulate history. Similarly, though generally at lower resolution, we are able to map common distinct features between histories that were measured with different techniques or at different locations. To match records, we used both manual visual inspection and an automated feature alignment algorithm. The laser logger recorded a measurement every $2-3 \mathrm{~mm}$, and our South Pole stratigraphic record includes meaningful, repeatable structure at the sub-centimeter depth scale. The analysis of millions of measurements with minimal information loss required the use of a fully automated synchronization scheme. We developed a procedure based on dynamic time warping and internal consistency error suppression (Bay and others, 2010).

The matching engine optimized for our South Pole laser dust logs did not perform as well when used to align sequences from different measurement techniques or sites. To match South Pole logger and EDC99 ice-core data with the algorithm, we smoothed the core data with a mild spline and used our Dome C optical log to corroborate feature matches at the centimeter scale. We verified and corrected a select subset of automated matching results by visual inspection for determining the primary age scale. Over some intervals, particularly in bubbly ice, only manual matching was effective. To aid visual inspection we used the MatchMaker MATLAB ice-core analysis utility (Rasmussen, 2006). At the South Pole, termination of the Last Glacial Maximum (LGM) into the Holocene epoch coincides with the bubble-hydrate transition at about 800-1150m where the optical signal amplitude changes by orders of magnitude. Definitive feature identification was challenging over this interval, and we required additional evidence below for stratigraphic control.

\section{RESULTS}

Logger profiles made in IceCube boreholes 21, 50, 66, 52, 10, 2, 86 and 14 between 2004 and 2011 (Fig. 2a) include some of the best-resolved records of Antarctic particulate stratigraphy available from the last glacial period. Figure $2 b$ shows the locations of the eight holes across IceCube. These laser profiles served as reference points to model layer undulations throughout the array, with isochrons depicted as topographic gradients in Figure 3a, and as layer contours in Figure $3 b-f$. At interstitial positions within the convex hull (smallest envelope) defined by logged holes, layering can be interpolated with standard gridding methods (natural neighbor, kriging). For stability and to extrapolate locations outside the hull, we used a modified ridge estimator in the MATLAB shareware program gridfit (D'Errico, 2005). Extrapolations outside reference data should of course be treated with caution. Since the first hole 21 log only reached $2113 \mathrm{~m}$ due to an instrument failure, the deepest $\sim 350 \mathrm{~m}$ in the southeast corner of the array must also be extrapolated. Inside the hull, the ridge estimator and natural-neighbor tessellation methods typically agreed within the 1-2 m absolute depth accuracy.

Figure 4 compares our borehole laser measurements with a record made from the Dome $C$ ice core using a state-ofthe-art CFA system. A linear scaling of logger photon counts gives good agreement with EDC99 $\mathrm{nssCa}^{2+}$. The roughly linear instrumental response is shown in Figure 5, which compares IceCube laser logging profiles to EDC99 and EPICA Dronning Maud Land (EDML) (Fischer and others, 2007) core dust. For the EDML comparison, we synchronized to core dust at only $\sim 1 \mathrm{~m}$ resolution. 

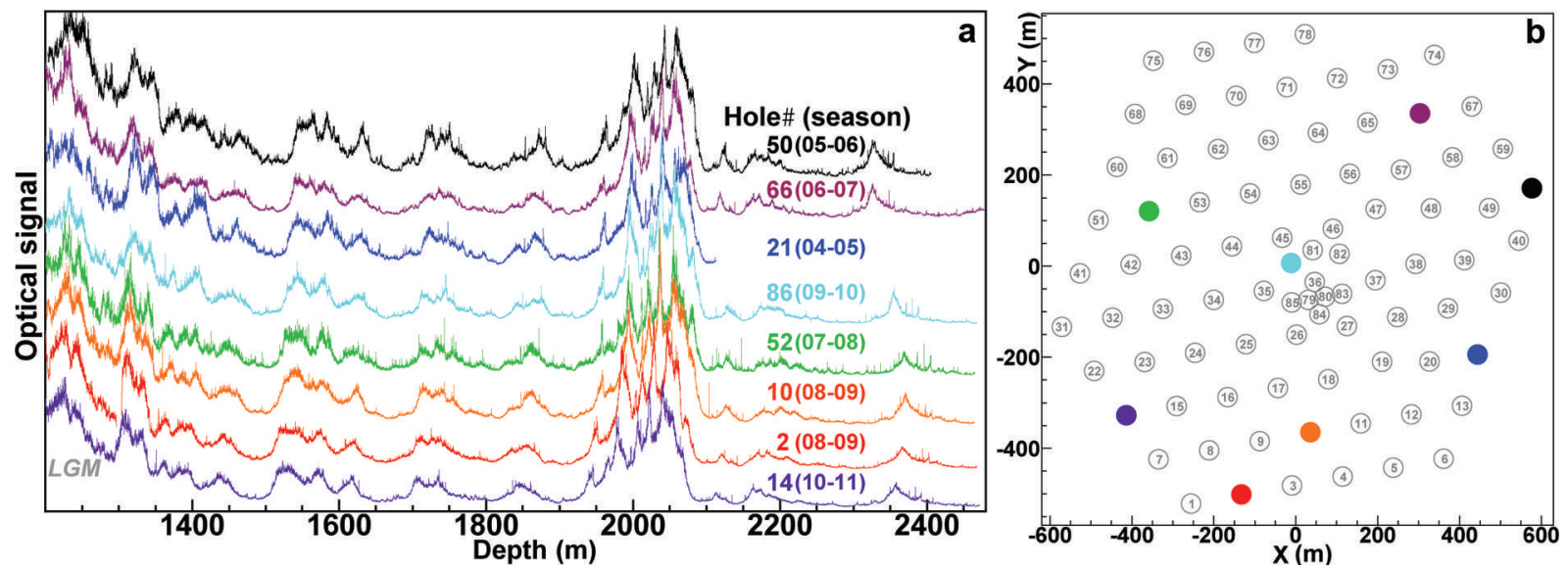

Fig. 2. (a) Borehole laser logging resolved sub-centimeter particulate features in repeated measurements. The early stages of the LGM are toward the left edge of the plot. The log of hole 21 stopped near $\sim 2100 \mathrm{~m}$ due to an instrument failure. (b) IceCube surface map and logged boreholes marked with solid color-coded circles. The $y$-axis points to Greenwich, UK, and as of 2011 the origin of the IceCube coordinate system was $509 \mathrm{~m}$ north and $982 \mathrm{~m}$ west of the South Pole $\left(1106 \mathrm{~m}\right.$ along $\left.63^{\circ} \mathrm{W}\right)$.

The most prominent dust feature at IceCube instrumented depths is marine isotope stage 4 (MIS4), a large peak between about 1950 and $2100 \mathrm{~m}$, corresponding to about $60-70 \mathrm{ka}$, which strongly affects detector response to particle physics events. Like the LGM at $\sim 25 \mathrm{ka}$, this cold interval and concomitant peak in dust are believed to result principally from a $41 \mathrm{ka}$ period minimum in the obliquity of the ecliptic (Berger, 1978) according to Milankovitch theories (Hays and others, 1976; Huybers and Wunsch, 2005) as well as extraterrestrial accretion theories (Muller and MacDonald, 1997) of orbitally controlled climate.
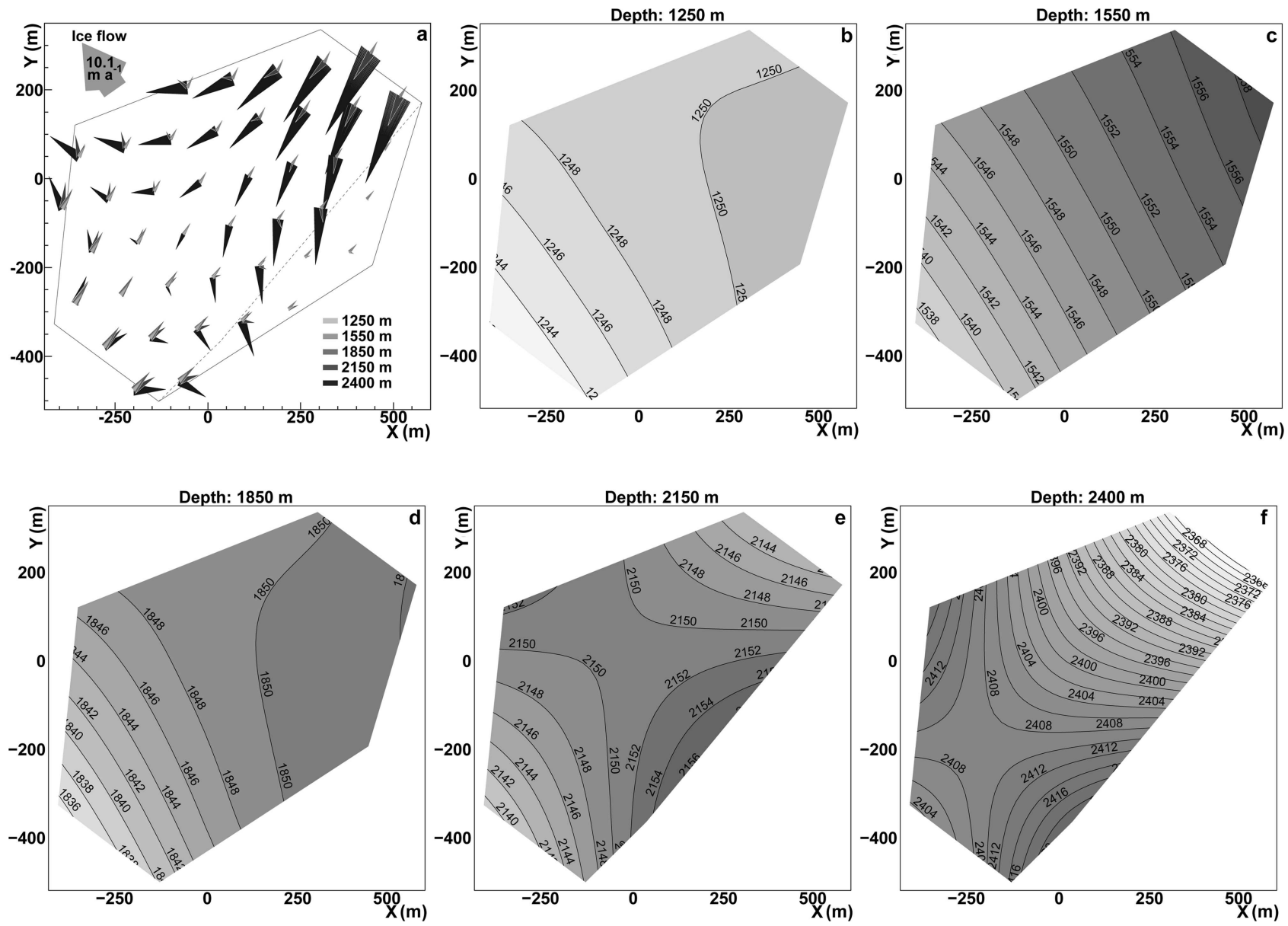

Fig. 3. Aerial view of dust layer tilt across IceCube at five depths, which shows the influence of basal topography likely increasing toward bedrock. (a) Arrows depict downhill direction and relative tilt magnitude of modeled isochrons. Layering outside convex hulls (polygons) defined by reference logging data is extrapolated and poorly constrained. Surface ice flow velocity is $10.1 \mathrm{ma}^{-1}$ along $320^{\circ}$ based on IceCube survey data. (b-f) Modeled dust isochrons at each depth, with contours indicating every $2 \mathrm{~m}$ change in elevation and lower levels shaded darker. Absolute depth accuracy of reference logs is 1-2 $\mathrm{m}$ and modeled layers do not necessarily intersect every control point. 


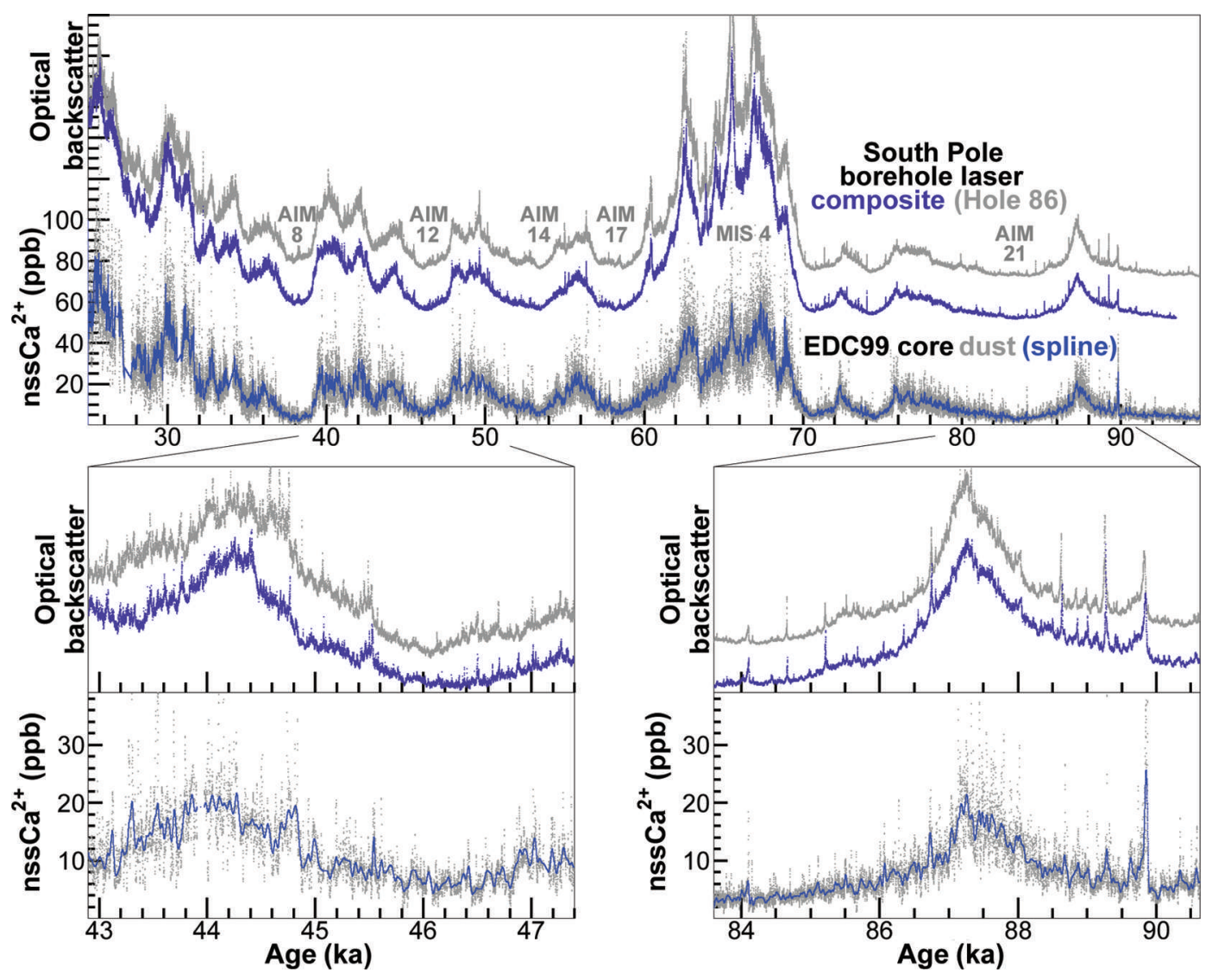

Fig. 4. Comparison between borehole laser records at South Pole (upper traces) and non-sea-salt calcium from continuous flow chemistry in Dome C EDC99 (lower traces; Lambert and others, 2012) over a $70 \mathrm{ka}$ interval on the EDC3 timescale. The light gray curve is the laser profile for hole 86 only; the violet curve is a composite average of all profiles. EDC99 non-sea-salt calcium measurements are plotted before (black) and after spline smoothing (blue). Marine isotope stage 4 and select Antarctic isotope maxima are labeled for context.

The EHWD provided a smooth transparent window through which we could make precision scans of in situ particulates, from clean water-filled boreholes with refractive index matching the ice $(\Delta n / n \approx 1.5 \%$ at $404 \mathrm{~nm}$; Gray, 1972; Price and Woschnagg, 2001). Scattering by residual air bubbles in the ice reduced the contrast of particulate scattering and made unambiguous identification of horizons increasingly difficult in layers shallower than the LGM around $\sim 1100$ to $1250 \mathrm{~m}$. Between 1200 and $1350 \mathrm{~m}$, we suppressed the contribution from bubble scattering with an ad hoc amplitude correction of $0.37 \%$ per meter of depth, which forced the logger signal profile to conform to the core dust profiles.

We have refined our South Pole age scale (AMANDA Collaboration, 1995; Price and others, 2000) for $90 \%$ of the ice depth and at multiple points traversing an area of order

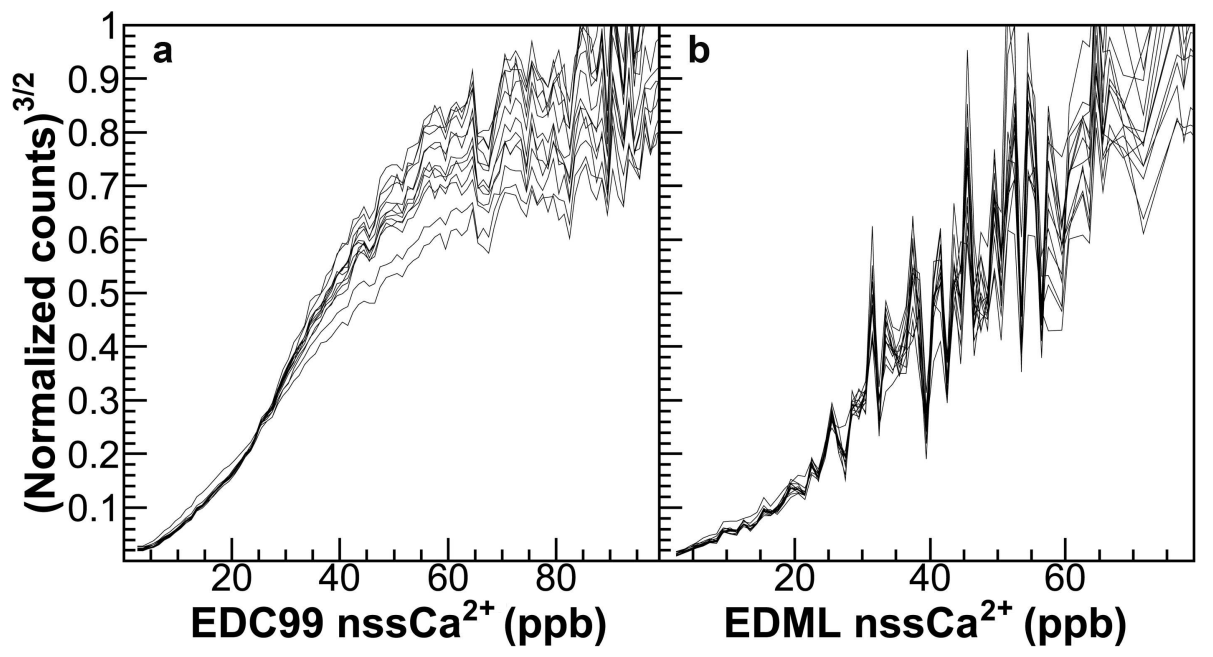

Fig. 5. The response of the logger in clear ice is approximately proportional to dust content. Signal amplitude for IceCube logging runs compared with synchronized core nssCa ${ }^{2+}$ from EDC99 (a) and EPICA Dronning Maud Land (b; $75^{\circ} \mathrm{S}, 0.067^{\circ}$ E; Fischer and others, 2007). Normalized logger signal counts have been raised to the power $3 / 2$ to relate scattering cross section (particle dimension squared) to mass (particle dimension cubed). 


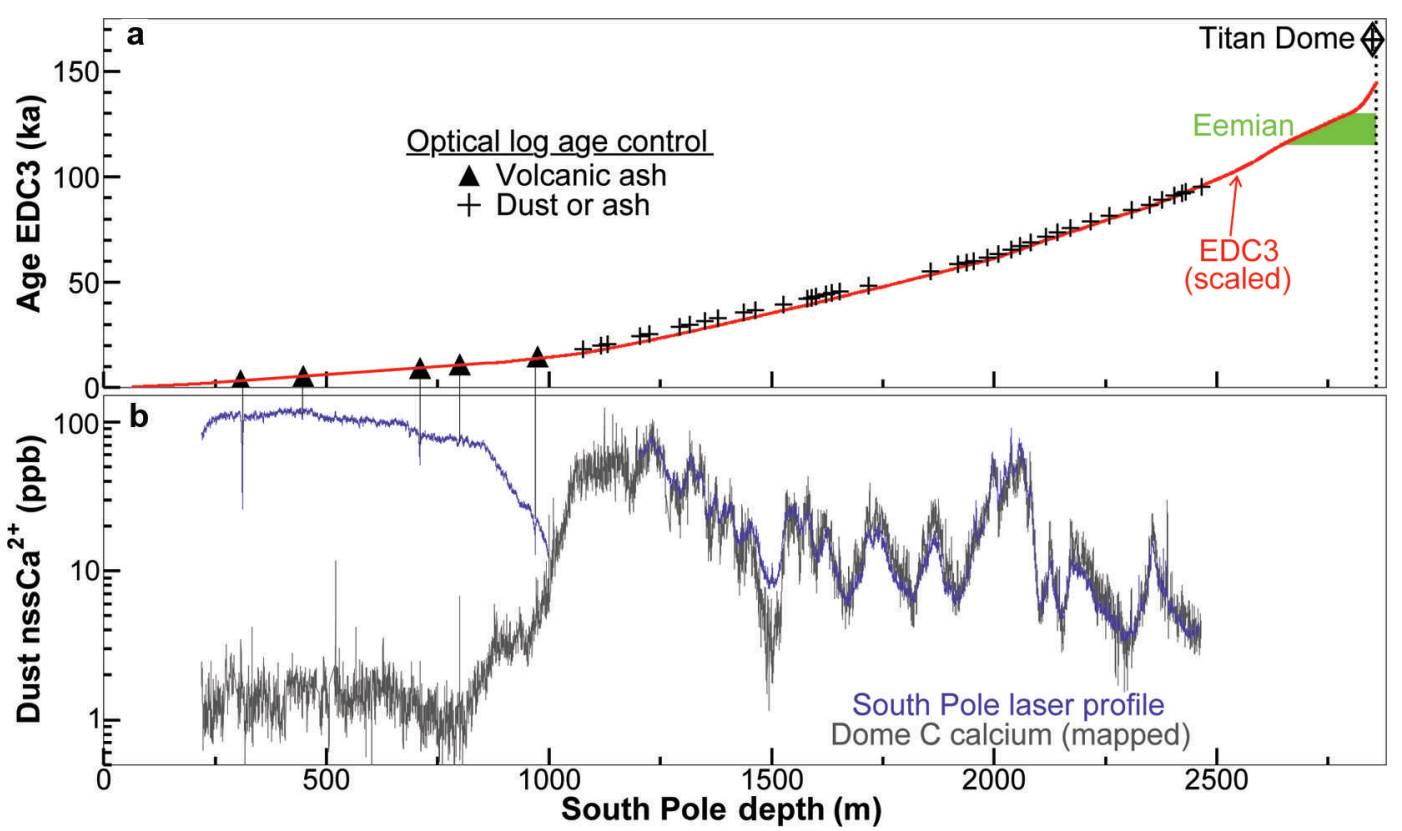

Fig. 6. (a) South Pole age versus depth, constructed by aligning laser profiles with corresponding ash and dust features at Dome C, on the EDC3 timescale. The red curve is a two-parameter quadratic depth transformation of Dome C age, which closely matches that of South Pole. An increase in accumulation rate is evident in the Dome $\mathrm{C}$ analog during the Eemian period, which is likely also represented at South Pole. A bedrock control point extrapolated from Titan Dome is taken to be $165 \mathrm{ka}$ at $2850 \mathrm{~m}$ (Siegert and Hodgkins, 2000). (b) Borehole laser dust logger signal, overlaid with spline-smoothed Dome $\mathrm{C} \mathrm{nssCa}{ }^{2+}$ manually synchronized with South Pole. Above $\sim 1000 \mathrm{~m}$ depth the logger signal is dominated by scattering from bubbles and absorption by volcanic ash.

one ice-sheet thickness in lateral extent (Figs 6-8). We used common features to link South Pole and Dome $\mathrm{C}$ and adopted the EDC3 timescale of Parrenin and others (2007a). At shallow and intermediate depths in bubbly ice, ash and dust features matched layers detected in our Dome $C$ dust log. We have also referred to early AMANDA measurements of absorption which indicated the falling edge of the LGM dust peak near $\sim 900 \mathrm{~m}$, with an absorption length comparable to the cleanest IceCube depths (Askebjer and others, 1997b). In the deep clear ice, we tied our laser profiles to $\mathrm{nssCa}^{2+}$ measurements in the Dome C ice core (Lambert and others, 2012). We manually verified a subset of algorithmic matches for the hole 86 log near the array center, to use for primary age. Figure 7 shows a comparison between manual and automated age curves. The primary age curve also includes a control point from aerial radar extrapolated from Titan Dome, located $\sim 100 \mathrm{~km}$ southsoutheast of South Pole, taken to be $165 \mathrm{ka}$ at $2850 \mathrm{~m}$ (Siegert and Hodgkins, 2000). After applying a simple two-parameter quadratic (forced through the origin) transformation of Dome C depth

$$
\mathbf{d}_{\text {scaled }}=0.383 \mathbf{d}_{\mathrm{EDC}}-5.7 \times 10^{-4} \mathbf{d}_{\mathrm{EDC}}^{2}
$$

EDC3 age tracks our South Pole curve. Figure 7 compares the new age-versus-depth scale with earlier AMANDA versions which were based on limited control data.

Decades of work with shallow South Pole cores have shown that the depths of recent historical volcanic events can vary by several meters within just a few lateral kilometers. Hamilton (2004) attributed this to topographically controlled micro-local accumulation variability. IceCube was surveyed every season, and depths are referenced
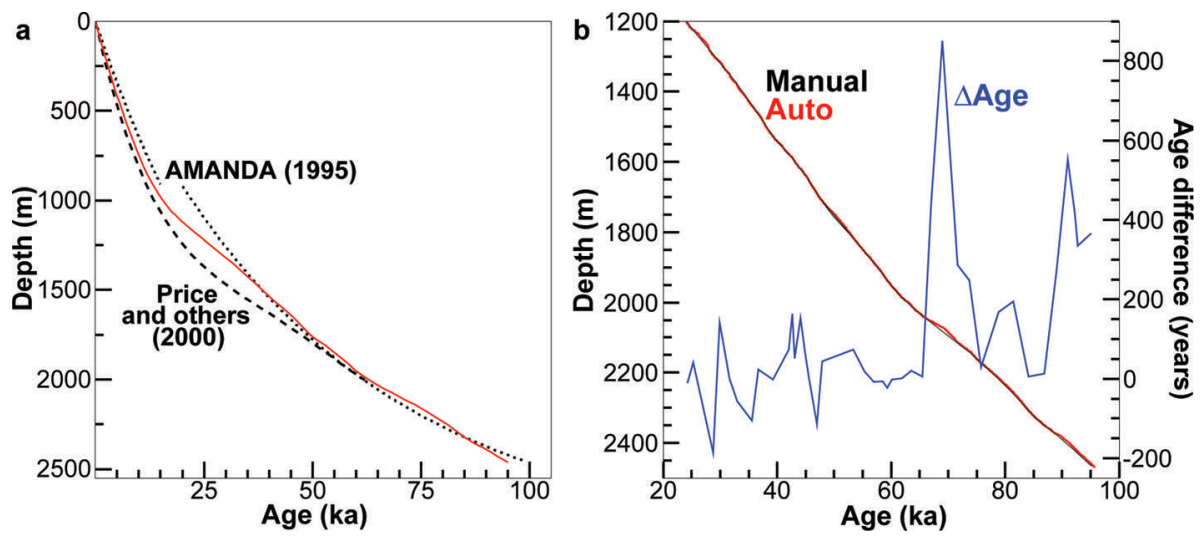

Fig. 7. (a) South Pole age versus depth presented here (solid), compared with previous versions (dotted, dashed) from AMANDA (AMANDA Collaboration, 1995; Price and others, 2000). (b) Primary South Pole age for hole 86 determined by manual inspection (black) compared with a spline-smoothed curve using the algorithm (red), and age discrepancy between the two methods (blue). The automated matching engine consistently mismatches the leading edge of MIS4 near $\sim 70 \mathrm{ka}$. 


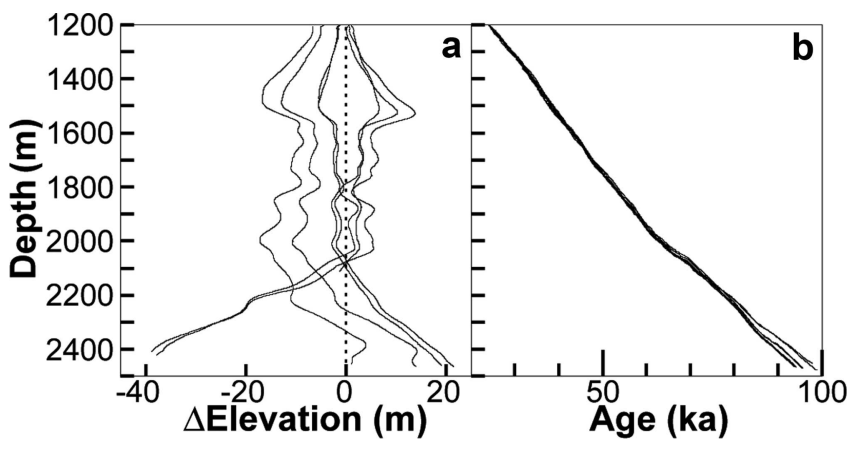

Fig. 8. (a) Internal variation of IceCube feature elevations across the kilometer array, relative to the central hole 86, used as control points for layer modeling in Figure 3. (b) South Pole age curves from automated synchronization of each log with EDC99 nssCa ${ }^{2+}$.

to a fixed elevation, which is the floor of the drilling tower for the first hole, No. 21. Figure 8a shows elevation variability of common features over the full depth range. Isochron tilting exceeds $70 \mathrm{~m}$ across the kilometer of IceCube for deeper features, probably as bedrock topography increasingly protrudes into the ice layering. Figure $8 \mathrm{~b}$ shows age-depth relationships from automated synchronization of the eight laser logs with EDC99 nssCa ${ }^{2+}$.

Figure 9 shows annual-layer thicknesses derived from the age-depth relationships in Figure 8. Variations in accumulation rate generally track climate changes, and the variations in our layer thicknesses are roughly consistent with dating-constrained flow models of the Dome $\mathrm{C}$ and Dome Fuji cores (Parrenin and others, 2007b).

For age control in the Holocene, we used the volcanic ash horizons detailed in Table 1, in which the ascribed eruptions deposited detectable ash at both sites. Ash layers are the most prominent optical features available for this period and are apparent in the raw signal in Figure 6b. Most layers could be detected easily in every laser profile we made. The two near $\sim 800 \mathrm{~m}$ were clear after comparison with Dome $C$ data using MatchMaker, and roughly agree with two echoes seen with surface radar (Besson and Kravchenko, 2013). Although discrete opaque layers that were isolated optically could also be the fallout from extraterrestrial sources or intense dust storms, for the purposes of reconstructing chronologies the strata need only be unambiguously matched between sites. Four of the layers were abundant enough in ice cores to have been microchemically investigated and traced to extra-Antarctic
Table 1. Opaque thin layers, presumed to be volcanic ash, used for age control in the shallow bubbly portion of the ice sheet. Four of the layers have been examined in the EDC99 core and were consistent with volcanoes of the South Sandwich Islands (SSI), Southern Andes (SA) and Marie Byrd Land (MBL) (Narcisi and others, 2005). The layer near $\sim 710 \mathrm{~m}$ dates the same as a layer in the Siple Dome core deemed to originate from a South American (sA) eruption (Kurbatov and others, 2006). The South Pole layers near $\sim 800 \mathrm{~m}$ and $\sim 810 \mathrm{~m}$ were not clearly identifiable in all logs and were matched as part of this study

\begin{tabular}{lccc}
\hline Depth (mean) & $\begin{array}{c}\text { EDC99 depth } \\
\mathrm{m}\end{array}$ & $\begin{array}{c}\text { Age } \\
\mathrm{ka}\end{array}$ & Provenance \\
$\mathrm{m}$ & & & \\
\hline 304.8-311.8 (307.6) & 132.6 & 3.6 & $\mathrm{SSI}$ \\
$443.4-447.9(445.0)$ & 185.3 & 5.4 & \\
$708.6-711.0(709.9)$ & 294.5 & 9.4 & $\mathrm{SA}$ \\
$\sim 800$ (faint) & 339.3 & 10.9 & $\mathrm{SSI}$ \\
$\sim 810$ (faint) & 346.2 & 11.1 & \\
$968.8-975.4(972.2)$ & 429.2 & 14.8 & \\
$979.8-985.9(982.8)$ & 434.7 & 15.1 & $\mathrm{MBL}$ \\
$1204.5-1212.5(1209.5)$ & 556.5 & 24.5 & \\
$1234.5-1243.1(1239.9)$ & 572.0 & 26.1 & $\mathrm{sA}$ \\
& & & \\
\hline
\end{tabular}

volcanoes of the South Sandwich Islands (Narcisi and others, 2005) and South America (Narcisi and others, 2005; Kurbatov and others, 2006). These ashfalls appear to have been widespread over much of the continent including West Antarctica (Bay and others, 2006), as well as the Southern Ocean (Nielsen and others, 2007), making them valuable horizons for dating.

Many eruptions, particularly the more powerful silicic variety, may be badly estimated (Toohey and others, 2013) or missed using core acidic volatiles and detectable only via tephra layers (Coulter and others, 2012). The Toba supereruption in Sumatra, Indonesia, occurred $\sim 74 \mathrm{ka} B \mathrm{BP}$ and is one of the most powerful eruptions known, possibly the largest volcanic event of the last $2 \mathrm{Ma}$ (Rose and Chesner, 1990). Toba has been implicated as the trigger for a volcanic winter and millennial-scale cold phase, and even a human population bottleneck detected in genomic studies (Rampino and Self, 1992; Ambrose, 1998). Yet Toba has never been conclusively identified in any Antarctic or Greenland ice core (Svensson and others, 2013). Recently, Storey and others (2012) used an astronomically calibrated ${ }^{40} \mathrm{Ar} /{ }^{39} \mathrm{Ar}$ Toba age to place the eruption between Antarctic isotope maxima 19 and 20. We plot this period in our optical logging data in
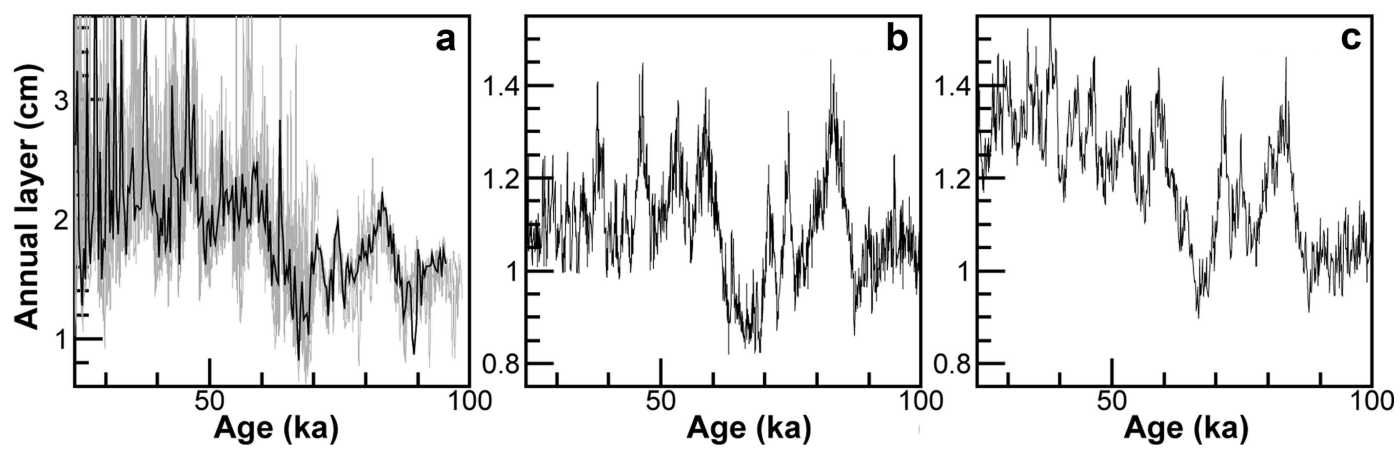

Fig. 9. (a) South Pole annual-layer thickness derived from the eight age curves in Figure 8 , spline-smoothed (gray) and 300 year average (black). Variations track layer thicknesses from East Antarctic flow models of Dome C (b) and Dome Fuji (c) (Parrenin and others, 2007b). 


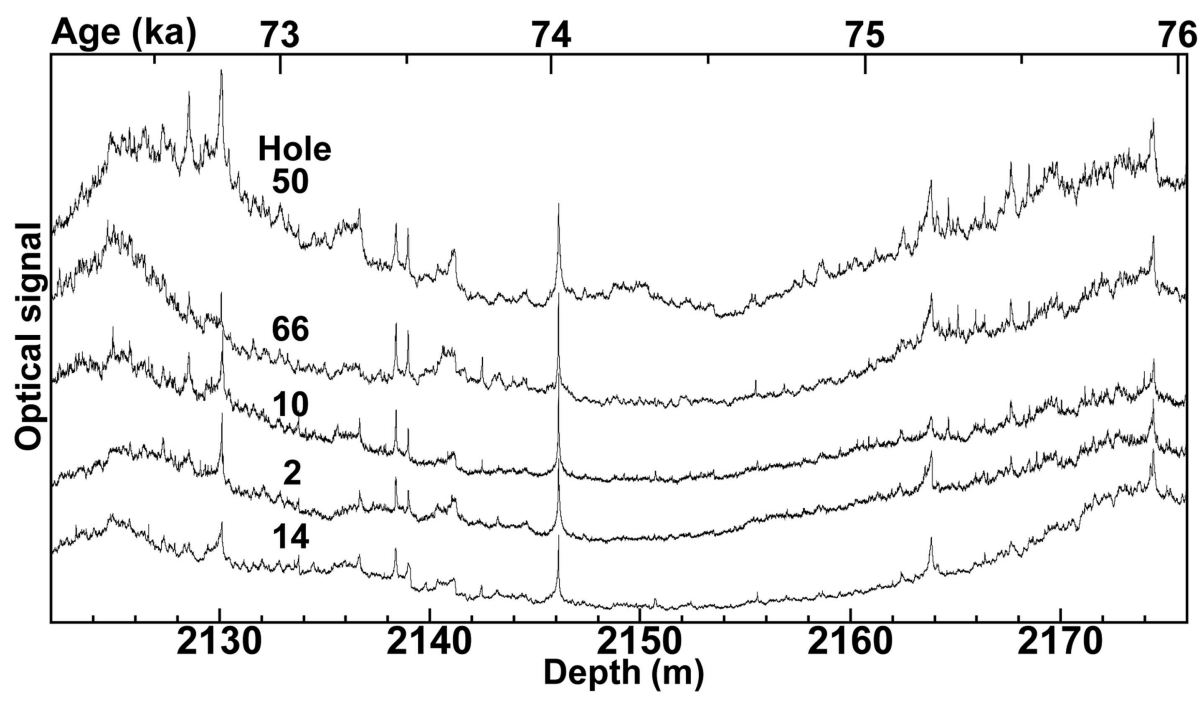

Fig. 10. South Pole laser logs over the interval now known to bracket Toba, the enigmatic supereruption which has never been found in an ice core. The five traces have been aligned to hole 86 depths using the automated matching algorithm. Thin spikes like that near $2146 \mathrm{~m}$ are most likely ash deposits, though heavier ashfalls tend to be products of nearby circum-Antarctic volcanoes.

Figure 10, which does include several upward spikes in signal likely indicating the presence of thin layers of volcanic ash. Heavier ashfalls tend to be the products of relatively nearby eruptions of modest intensity, which partly explains why Toba has so far eluded investigators.

\section{DISCUSSION}

In addition to mineral grains and volcanic ash, natural ice impurities include salts, acids and soot (He and Price, 1998). The particulate absorption and scattering that are sensed with optical methods are the result of varying particle number densities, sizes, shapes and albedos. Although impurity deposition over the continent is remarkably uniform, the particulate records at different Antarctic sites are not perfect analogs of each other but depend on location, elevation, accumulation and atmospheric circulation patterns. The composition, scattering efficiency and absorption efficiency of impurities likely also vary in time with climate (e.g. because of a changing contribution of dust from Australia relative to South America (Lambert and others, 2011)). Some of the nonlinearity in Figure 5 could reflect a lower average dust albedo at high concentrations, or local variations. In extremely pure ice, backscattered light is a good tracer of mineral dust content, though the linearity can be expected to eventually break down at high enough number densities.

Although the intrinsic resolution of the logger is $\sim 2-3 \mathrm{~mm}$, the fixed $60^{\circ}$ fan spanned by the laser line source produces an average over depositional noise (surface roughness) embedded in the stratigraphic record. The logger could be made more effective with laser imaging techniques like those employed in scanning lidar systems. By sweeping the beam through $360^{\circ}$ of the horizon and preserving azimuthal information, future designs could help disentangle and extract surface roughness information for an improved dust record.

Snow accumulation at South Pole is unusually high, considering its elevation and mean annual temperature, because of frequent inland penetration by low-pressure systems from the Weddell Sea as well as the Pacific sector.
Apart from accumulation rate, the glaciology of South Pole has much in common with the Vostok (East Antarctica) icecore site. Both locations are relatively cold, flat 'flank' sites far from an ice divide or dome. Horizontal flow at both sites is substantial ( $3 \mathrm{~m} \mathrm{a}^{-1}$ at Vostok and $10 \mathrm{~m} \mathrm{a}^{-1}$ at South Pole) and may involve converging ice streams. Intervals of the Vostok core show a strong girdle fabric (Lipenkov and others, 1989; Obbard and Baker, 2007) in which the ice is subjected to pure shear and crystal $c$-axes fall in a vertical plane perpendicular to the direction of flow. Studies of aerial radar have suggested a disrupted South Pole stratigraphy (Bingham and others, 2007) and the possibility that tributaries of nearby ice streams have migrated through an area where flow velocities have varied over time (personal communication from D. Blankenship, 2011). Knowledge of the South Pole area is incomplete, based on limited radar and satellite surface velocity measurements south of $87^{\circ} \mathrm{S}$. New aerogeophysical surveys would allow us to fit our maps into the larger context, and comparison with our stratigraphy could provide new insights for understanding englacial radar attenuation and interpreting radargrams.

\section{CONCLUSIONS}

IceCube logged eight hot-water boreholes using a highresolution laser dust logger, permitting detailed glaciological reconstructions without local core samples. Optical backscattering in clear ice matches EDC99 ice-core non-sea-salt calcium, over a last glacial climate record which is intact back to at least $100 \mathrm{ka}$ at South Pole. We see no stratigraphic folding to $87 \%$ depth to bedrock across IceCube, although we found undulations of internal layering of order $\sim 10 \%$ $(0.1 \mathrm{~km}$ elevation change over $1 \mathrm{~km})$ in the cross-flow direction, which are consistent with radargrams. South Pole annual-layer history is consistent with accumulation variability in East Antarctic ice cores. Several volcanic ash layers match across the continent and we examined the interval around Toba for candidate tephra deposits.

Together with hot-water or mechanical fast access drilling, optical logging can be used to determine age, stratigraphic integrity and scientific potential of a site before 
devoting the resources of a coring mission. A detailed particulate depth profile can be used to immediately date any site on the continent precisely and confidently. A primary goal of the International Partnerships in Ice Core Sciences is to obtain a core reaching back $>1.5 \mathrm{Ma}$, in ice likely to be found in the deep East Antarctic ice sheet (Jones, 2007). Such a project will require a substantial reconnaissance effort to determine optimal sites for drilling before a deep-coring drill is fielded. Aerial radar is not always reliable for absolute age determination, especially in the deepest parts of an ice sheet where radar echo layers can be missing or difficult to interpret (Drews and others, 2009). An expeditionary campaign which combines rapid access drilling and borehole logging may be indispensable for prospecting purposes.

The USA has maintained a presence at South Pole since 1956, culminating in the modern year-round research station. Efforts are underway to develop an intermediate coring drill and recover a $\sim 1500 \mathrm{~m}$ South Pole ice core, aimed at sampling atmospheric gases of the last $\sim 40 \mathrm{ka}$ (personal communication from E. Saltzmann, 2011). If drilled to bedrock a core would likely obtain ice from the Eemian period, although we cannot exclude stratigraphic disturbance in the bottom few hundred meters. An ice core offers potential synergies with IceCube and other South Pole physics projects such as the Askaryan Radio Array, a prototype ultra-high-energy neutrino detector. Core samples could be of particular interest to radio experiments for characterizing the soluble ionic impurities, ice fabric, density, etc., that affect radio clarity (Kravchenko and others, 2011). South Pole core samples can be stored on site and could in principle be drilled during winter. A number of shallow South Pole cores have already been retrieved, the longest $361 \mathrm{~m}$ (Palais and others, 1987) and a few thousand years in age, and the new core need not be far removed from South Pole Station to avoid anthropogenic contamination. If the main core is drilled near the astrophysics arrays, the remnant borehole could serve as an access point for optical and radio calibration beacons.

\section{ACKNOWLEDGEMENTS}

We thank Nathan Bramall, Robert Rohde, Andres Morey, Tom Ham, Kurt Cuffey, Dave Ferris, Michael Solarz, the EPICA Collaboration, the WAIS Divide Project members and the US National Ice Core Laboratory. We acknowledge the support from the following agencies: US National Science Foundation (NSF) Office of Polar Programs, NSF Physics Division, University of Wisconsin Alumni Research Foundation, Grid Laboratory Of Wisconsin (GLOW) grid infrastructure at the University of Wisconsin-Madison, Open Science Grid (OSG) grid infrastructure; US Department of Energy, National Energy Research Scientific Computing Center, Louisiana Optical Network Initiative (LONI) grid computing resources; Natural Sciences and Engineering Research Council of Canada, Compute Canada and Compute West High Performance Computing; Swedish Research Council, Swedish Polar Research Secretariat, Swedish National Infrastructure for Computing (SNIC), Knut and Alice Wallenberg Foundation, Sweden; German Ministry for Education and Research (BMBF), Deutsche Forschungsgemeinschaft (DFG), Helmholtz Alliance for Astroparticle Physics (HAP), Research Department of Plasmas with Complex Interactions (Bochum), Germany; Fund for Scientific Research (FNRS-FWO), FWO Odysseus programme, Flanders Institute to encourage scientific and technological research in industry (IWT), Belgian Federal Science Policy Office (Belspo); University of Oxford, UK; Marsden Fund, New Zealand; Australian Research Council; Japan Society for Promotion of Science (JSPS); Swiss National Science Foundation (SNSF), Switzerland.

\section{REFERENCES}

Ackermann M and 116 others (2006) Optical properties of deep glacial ice at the South Pole. J. Geophys. Res., 111(D13), D13203 (doi: 10.1029/2005JD006687)

AMANDA Collaboration (1995) On the age vs depth and optical clarity of deep ice at the South Pole. J. Glaciol., 41(139), 445-454

AMANDA Collaboration (2001) Observation of high-energy neutrinos using Cerenkov detectors embedded deep in Antarctic ice. Nature, 410(6827), 441-443 (doi: 10.1038/35068509)

Ambrose SH (1998) Late Pleistocene human population bottlenecks, volcanic winter, and differentiation of modern humans. J. Human Evol., 34(6), 623-651 (doi: 10.1006/jhev.1998.0219)

Askebjer $\mathrm{P}$ and 29 others (1995) Optical properties of the South Pole ice at depths between 0.8 and 1 kilometer. Science, 267(5201), 1147-1150 (doi: 10.1126/science.267.5201.1147)

Askebjer P and 35 others (1997a) Optical properties of deep ice at the South Pole: absorption. Appl. Opt., 36(18), 4168-4180 (doi: 10.1364/AO.36.004168)

Askebjer P and 34 others (1997b) UV and optical light transmission properties in deep ice at the South Pole. Geophys. Res. Lett., 24(11), 1355-1358 (doi: 10.1029/97GL01246)

Barkov NI and Lipenkov VYa (1985) Kolichestvennaya harakteristika struktury I'da do glubiny $1400 \mathrm{~m}$ v rajone stantsii Vostok v Antarktide [Numerical characteristics of ice structure down to a depth of 1,400 $\mathrm{m}$ in the region of Vostok Station, Antarctica]. Mater. Glyatsiol. Issled. 51, 178

Bay RC, Price PB, Clow GD and Gow AJ (2001) Climate logging with a new rapid optical technique at Siple Dome. Geophys. Res. Lett., 28(24), 4635-4638 (doi: 10.1029/2001GL013763)

Bay RC and 6 others (2006) Globally synchronous ice core volcanic tracers and abrupt cooling during the last glacial period. J. Geophys. Res., 111(D11), D11108 (doi: 10.1029/ 2005JD006306)

Bay RC, Rohde RA, Price PB and Bramall NE (2010) South Pole paleowind from automated synthesis of ice core records. J. Geophys. Res., 115(D14), D14126 (doi: 10.1029/ 2009JD013741)

Berger AL (1978) Long-term variations of daily insolation and Quaternary climatic changes. J. Atmos. Sci., 35(12), 2362-2367 (doi: 10.1175/1520-0469(1978)035<2362:LTVODI>2.0.CO;2)

Bigler M, Röthlisberger R, Lambert F, Stocker TF and Wagenbach D (2006) Aerosol deposited in East Antarctica over the last glacial cycle: detailed apportionment of continental and sea-salt contributions. J. Geophys. Res., 111(D8), D08205 (doi: 10.1029/2005JD006469)

Bingham RG, Siegert MJ, Young DA and Blankenship DD (2007) Organized flow from the South Pole to the Filchner-Ronne ice shelf: an assessment of balance velocities in interior East Antarctica using radio echo sounding data. J. Geophys. Res., 112(F3), F03S26 (doi: 10.1029/2006JF000556)

Bramall NE, Bay RC, Woschnagg K, Rohde RA and Price PB (2005) A deep high-resolution optical log of dust, ash, and stratigraphy in South Pole glacial ice. Geophys. Res. Lett., 32(21), L21815 (doi: 10.1029/2005GL024236)

Coulter SE and 8 others (2012) Holocene tephras highlight complexity of volcanic signals in Greenland ice cores. J. Geophys. Res., 117(D21), D21303 (doi: 10.1029/2012JD017698)

D'Errico J (2005) Surface fitting using gridfit. MATLAB Central File Exchange http://www.mathworks.es/matlabcentral/ fileexchange/8998-surface-fitting-using-gridfit 
Delmonte B and 6 others (2008) Aeolian dust in East Antarctica (EPICA-Dome $\mathrm{C}$ and Vostok): provenance during glacial ages over the last 800 kyr. Geophys. Res. Lett., 35(7), L07703 (doi: 10.1029/2008GL033382)

Drews $\mathrm{R}$ and 7 others (2009) Layer disturbances and the radio-echo free zone in ice sheets. Cryosphere, 3(2), 195-203 (doi: 10.5194/tcd-3-307-2009)

Fischer $\mathrm{H}$ and 28 others (2007) Reconstruction of millennial changes in dust emission, transport and regional sea ice coverage using the deep EPICA ice cores from the Atlantic and Indian Ocean sector of Antarctica. Earth Planet. Sci. Lett., 260(1-2), 340-354 (doi: 10.1016/j.epsl.2007.06.014)

Fudge TJ and Smith BE (2010) Light propagation in firn: application to borehole video. J. Glaciol., 56(198), 614-624 (doi: 10.3189/ 002214310793146205)

Gabrielli P and 11 others (2010) A major glacial-interglacial change in aeolian dust composition inferred from Rare Earth Elements in Antarctic ice. Quat. Sci. Rev., 29(1-2), 265-273 (doi: 10.1016/j.quascirev.2009.09.002)

Gray DE ed. (1972) American Institute of Physics handbook, 3rd edn. McGraw-Hill, New York

Hamilton GS (2004) Topographic control of regional accumulation rate variability at South Pole and implications for ice-core interpretation. Ann. Glaciol., 39, 214-218 (doi: 10.3189/172756404781814050)

Hays JD, Imbrie J and Shackleton N (1976) Variations in the Earth's orbit: pacemaker of the ice ages. Science, 194(4270), $1121-1132$

He YD and Price PB (1998) Remote sensing of dust in deep ice at the South Pole. J. Geophys. Res., 103(D14), 17 041-17 056 (doi: 10.1029/98JD01643)

Huybers P and Wunsch C (2005) Obliquity pacing of the late Pleistocene glacial terminations. Nature, 434(7032), 491-494 (doi: 10.1038/nature03401)

IceCube Collaboration (2006) First year performance of the IceCube neutrino telescope. Astropart. Phys., 26(3), 155-173 (doi: 10.1016/j.astropartphys.2006.06.007)

IceCube Collaboration (2009) The IceCube data acquisition system: signal capture, digitization, and timestamping. Nucl. Instrum. Meth. Phys. Res. A, 601(3), 294-316 (doi: 10.1016/j.nima. 2009.01.001)

IceCube Collaboration (2010) Measurement of sound speed vs. depth in South Pole ice for neutrino astronomy. Astropart. Phys., 33(5-6), 277-286 (doi: 10.1016/j.astropartphys.2010.01.012)

IceCube Collaboration (2011) Measurement of acoustic attenuation in South Pole ice. Astropart. Phys., 34(6), 382-393 (doi: 10.1016/j.astropartphys.2010.10.003)

IceCube Collaboration (2013) Measurement of South Pole ice transparency with the IceCube LED calibration system. Nucl. Instrum. Meth. Phys. Res. A, 711, 73-89 (doi: 10.1016/ j.nima.2013.01.054)

Jones N (2007) Polar research: buried treasure. Nature, 446(7132), 126-128 (doi: 10.1038/446126a)

Jouzel J and 31 others (2007) Orbital and millennial Antarctic climate variability over the past 800,000 years. Science, 317(5839), 793-796 (doi: 10.1126/science.1141038)

Kravchenko I, Besson D, Ramos A and Remmers J (2011) Radio frequency birefringence in south polar ice and implications for neutrino reconstruction. Astropart. Phys., 34(10), 755-768 (doi: 10.1016/j.astropartphys.2011.01.008)

Kurbatov AV and 6 others (2006) A 12,000 year record of explosive volcanism in the Siple Dome Ice Core, West Antarctica. J. Geophys. Res., 111(D12), D12307 (doi: 10.1029/2005JD006072)

Lambert F, Bigler M, Steffensen JP, Hutterli M and Fischer H (2011) The calcium-dust relationship in high-resolution data from Dome C, Antarctica. Climate Past Discuss., 7(2), 1113-1137 (doi: 10.5194/cpd-7-1113-2011)

Lambert F, Bigler M, Steffensen JP, Hutterli M and Fischer H (2012) Centennial mineral dust variability in high-resolution ice core data from Dome C, Antarctica. Climate Past, 8(2), 609-623 (doi: 10.5194/cp-8-609-2012)

Legrand M and Mayewski P (1997) Glaciochemistry of polar ice cores: a review. Rev. Geophys., 35(3), 219-243 (doi: 10.1029/ 96RG03527)

Li F, Ginoux P and Ramaswamy V (2008) Distribution, transport, and deposition of mineral dust in the Southern Ocean and Antarctica: contribution of major sources. J. Geophys. Res., 113(D10), D10207 (doi: 10.1029/2007JD009190)

Li F, Ramaswamy V, Ginoux P, Broccoli AJ, Delworth T and Zeng F (2010) Toward understanding the dust deposition in Antarctica during the Last Glacial Maximum: sensitivity studies on plausible causes. J. Geophys. Res., 115(D24), D24120 (doi: 10.1029/2010JD014791)

Lipenkov VYa, Barkov NI, Duval P and Pimienta P (1989) Crystalline texture of the $2083 \mathrm{~m}$ ice core at Vostok Station, Antarctica. J. Glaciol., 35(121), 392-398

Markov MA and Zheleznykh IM (1986) Large-scale Cherenkov detectors in ocean, atmosphere and ice. Nucl. Instrum. Meth. Phys. Res. A, 248(1), 242-251

Muller RA and MacDonald G) (1997) Glacial cycles and astronomical forcing. Science, 277(5323), 215-218 (doi: 10.1126/science.277.5323.215)

Narcisi B, Petit JR, Delmonte B, Basile-Doelsch I and Maggi V (2005) Characteristics and sources of tephra layers in the EPICA-Dome C ice record (East Antarctica): implications for past atmospheric circulation and ice core stratigraphic correlations. Earth Planet. Sci. Lett., 239(3-4), 253-265 (doi: 10.1016/ j.epsl.2005.09.005)

Nielsen SHH, Hodell DA, Kamenov G, Guilderson T and Perfit MR (2007) Origin and significance of ice-rafted detritus in the Atlantic sector of the Southern Ocean. Geochem. Geophys. Geosyst., 8(12), Q12005 (doi: 10.1029/2007GC001618)

Obbard R and Baker I (2007) The microstructure of meteoric ice from Vostok, Antarctica. J. Glaciol., 53(180), 41-62 (doi: 10.3189/172756507781833901)

Palais JM, Mosley-Thompson E and Thomas E (1987) Correlation of a 3,200 year old tephra in ice cores from Vostok and South Pole stations, Antarctica. Geophys. Res. Lett., 14(8), 804-807 (doi: 10.1029/GL014i008p00804)

Parrenin F and 26 others (2007a) The EDC3 chronology for the EPICA Dome C ice core. Climate Past, 3(3), 485-497 (doi: 10.5194/cp-3-485-2007)

Parrenin F and 15 others (2007b) 1-D-ice flow modelling at EPICA Dome C and Dome Fuji, East Antarctica. Climate Past, 3(2), 243-259 (doi: 10.5194/cp-3-243-2007)

Price PB and Woschnagg K (2001) Role of group and phase velocity in high-energy neutrino observatories. Astropart. Phys., 15(1), 97-100 (doi: 10.1016/S0927-6505(00)00142-0)

Price PB, Woschnagg K and Chirkin D (2000) Age vs depth of glacial ice at South Pole. Geophys. Res. Lett., 27(14), 2129-2132 (doi: 10.1029/2000GL011351)

Price PB and 9 others (2002) Temperature profile for glacial ice at the South Pole: implications for life in a nearby subglacial lake. Proc. Natl Acad. Sci. USA (PNAS), 99(12), 7844-7847 (doi: 10.1073/pnas.082238999)

Rampino MR and Self S (1992) Volcanic winter and accelerated glaciation following the Toba super-eruption. Nature, 359(6390), 50-52 (doi: 10.1038/359050a0)

Rasmussen SO (2006) Improvement, dating and analysis of Greenland ice core stratigraphies. (PhD thesis, University of Copenhagen)

Rose WI and Chesner CA (1990) Worldwide dispersal of ash and gases from earth's largest known eruption: Toba, Sumatra, 75 ka. Global Planet. Change, 3(3), 269-275 (doi: 10.1016/09218181(90)90023-6)

Siegert MJ and Hodgkins R (2000) A stratigraphic link across 1100 $\mathrm{km}$ of the Antarctic ice sheet between the Vostok ice-core site and Titan Dome (near South Pole). Geophys. Res. Lett., 27(14), 2133-2136 (doi: 10.1029/2000GL008479) 
Sime LC, Wolff EW, Oliver KIC and Tindall JC (2009) Evidence for warmer interglacials in East Antarctic ice cores. Nature, 462(7271), 342-345 (doi: 10.1038/nature08564)

Storey M, Roberts RG and Saidin M (2012) Astronomically calibrated $40 \mathrm{Ar} / 39 \mathrm{Ar}$ age for the Toba supereruption and global synchronization of late Quaternary records. Proc. Natl Acad. Sci. USA (PNAS), 109(46), 18684-18688 (doi: 10.1073/ pnas.1208178109)

Svensson A and 25 others (2013) Direct linking of Greenland and Antarctic ice cores at the Toba eruption (74 ka BP). Climate Past, 9(2), 749-766 (doi: 10.5194/cp-9-749-2013)
Toohey M, Kruger K and Timmreck C (2013) Volcanic sulfate deposition to Greenland and Antarctica: a modeling sensitivity study. J. Geophys. Res., 118(10), 4788-4800 (doi: 10.1002/ jgrd.50428)

Uchida T, Shimada W, Hondoh T, Mae S and Barkov NI (1995) Refractive-index measurements of natural air-hydrate crystals in an Antarctic ice sheet. Appl. Opt., 34(25), 5746-5749 (doi: 10.1364/AO.34.005746)

Woschnagg K and Price PB (2001) Temperature dependence of absorption in ice at $532 \mathrm{~nm}$. Appl. Opt., 40(15), 2496-2500 (doi: 10.1364/AO.40.002496)

\section{APPENDIX}

\section{The IceCube Collaboration}

M.G. Aartsen, ${ }^{2}$ R. Abbasi, ${ }^{27}$ Y. Abdou, ${ }^{22}$ M. Ackermann, ${ }^{41}$ J. Adams, ${ }^{15}$ J.A. Aguilar, ${ }^{21}$ M. Ahlers, ${ }^{27}$ D. Altmann, ${ }^{9}$ J. Auffenberg, ${ }^{27}$ X. Bai, ${ }^{31, a}$ M. Baker, ${ }^{27}$ S.W. Barwick, ${ }^{23}$ V. Baum, ${ }^{28}$ R. Bay, ${ }^{7}$ J.J. Beatty, ${ }^{17,}{ }^{18} \mathrm{~S}$. Bechet, $^{12}$ K.-H. Becker, ${ }^{40}$ J. Becker Tjus, ${ }^{10}$ M. Bell, ${ }^{38}$ M.L. Benabderrahmane, ${ }^{41}$ S. BenZvi, ${ }^{27}$ J. Berdermann, ${ }^{41}$ P. Berghaus, ${ }^{41}$ D. Berley, ${ }^{16}$ E. Bernardini, ${ }^{41}$ A. Bernhard ${ }^{30}$ D. Bertrand, ${ }^{12}$ D.Z. Besson, ${ }^{25}$ G. Binder, ${ }^{8,7}$ D. Bindig, ${ }^{40}$ M. Bissok, ${ }^{1}$ E. Blaufuss, ${ }^{16}$ J. Blumenthal, ${ }^{1}$ D.J. Boersma, ${ }^{39}$ S. Bohaichuk, ${ }^{20}$ C. Bohm, ${ }^{34}$ D. Bose, ${ }^{13}$ S. Böser, ${ }^{11}$ O. Botner, ${ }^{39}$ L. Brayeur, ${ }^{13}$ H.-P. Bretz, ${ }^{41}$ A.M. Brown, ${ }^{15}$ R. Bruijn, ${ }^{24}$ J. Brunner, ${ }^{41}$ M. Carson, ${ }^{22}$ J. Casey, ${ }^{5}$ M. Casier, ${ }^{13}$ J. Cherwinka, ${ }^{27}$ D. Chirkin, ${ }^{27}$ A. Christov, ${ }^{21}$ B. Christy, ${ }^{16}$ K. Clark, ${ }^{38}$ F. Clevermann, ${ }^{19}$ S. Coenders, ${ }^{1}$ S. Cohen, ${ }^{24}$ D.F. Cowen, ${ }^{38,} 37$ A.H. Cruz Silva, ${ }^{41}$ M. Danninger, ${ }^{34}$ J. Daughhetee, ${ }^{5}$ J.C. Davis, ${ }^{17}$ C. De Clercq, ${ }^{13}$ S. De Ridder, ${ }^{22}$ P. Desiati, ${ }^{27}$ M. de With, ${ }^{9}$ T. DeYoung, ${ }^{38}$ J.C. Díaz-Vélez, ${ }^{27}$ M. Dunkman, ${ }^{38}$ R. Eagan, ${ }^{38}$ B. Eberhardt, ${ }^{28}$ J. Eisch, ${ }^{27}$ R.W. Ellsworth, ${ }^{16}$ S. Euler, ${ }^{1}$ P.A. Evenson, ${ }^{31}$ O. Fadiran, ${ }^{27}$ A.R. Fazely, ${ }^{6}$ A. Fedynitch, ${ }^{10}$ J. Feintzeig, ${ }^{27}$ T. Feusels, ${ }^{22}$ K. Filimonov, ${ }^{7}$ C. Finley, ${ }^{34}$ T. Fischer-Wasels, ${ }^{40}$ S. Flis, $^{34}$ A. Franckowiak, ${ }^{11}$ R. Franke, ${ }^{41}$ K. Frantzen, ${ }^{19}$ T. Fuchs, ${ }^{19}$ T.K. Gaisser, ${ }^{31}$ J. Gallagher, ${ }^{26}$ L. Gerhardt, ${ }^{8,7}$ L. Gladstone, ${ }^{27}$ T. Glüsenkamp, ${ }^{41}$ A. Goldschmidt, ${ }^{8}$ G. Golup, ${ }^{13}$ J.G. Gonzalez, ${ }^{31}$ J.A. Goodman, ${ }^{16}$ D. Góra, ${ }^{41}$ D. Grant, ${ }^{20}$ A. Groß ${ }^{30}$ M. Gurtner, ${ }^{40}$ C. Ha, ${ }^{8,7}$ A. Haj Ismail, ${ }^{22}$ P. Hallen, ${ }^{1}$ A. Hallgren, ${ }^{39}$ F. Halzen, ${ }^{27}$ K. Hanson, ${ }^{12}$ D. Heereman, ${ }^{12}$ D. Heinen, ${ }^{1}$ K. Helbing, ${ }^{40}$ R. Hellauer, ${ }^{16}$ S. Hickford, ${ }^{15}$ G.C. Hill, ${ }^{2}$ K.D. Hoffman, ${ }^{16}$ R. Hoffmann, ${ }^{40}$ A. Homeier, ${ }^{11}$ K. Hoshina, ${ }^{27}$ W. Huelsnitz, ${ }^{16, b}$ P.O. Hulth, ${ }^{34}$ K. Hultqvist, ${ }^{34}$ S. Hussain, ${ }^{31}$ A. Ishihara, ${ }^{14}$ E. Jacobi, ${ }^{41}$ J. Jacobsen, ${ }^{27}$ K. Jagielski, ${ }^{1}$ G.S. Japaridze, ${ }^{4}$ K. Jero, ${ }^{27}$ O. Jlelati, ${ }^{22}$ B. Kaminsky, ${ }^{41}$ A. Kappes, ${ }^{9}$ T. Karg, ${ }^{41}$ A. Karle, ${ }^{27}$ J.L. Kelley, ${ }^{27}$ J. Kiryluk, ${ }^{35}$ F. Kislat, ${ }^{41}$ J. Kläs, ${ }^{40}$ S.R. Klein, ${ }^{8,7}$ J.-H. Köhne, ${ }^{19}$ G. Kohnen, ${ }^{29}$ H. Kolanoski, ${ }^{9}$ L. Köpke, ${ }^{28}$ C. Kopper, ${ }^{27}$ S. Kopper, ${ }^{40}$ D.J. Koskinen, ${ }^{38}$ M. Kowalski, ${ }^{11}$ M. Krasberg, ${ }^{27}$ K. Krings, ${ }^{1}$ G. Kroll, ${ }^{28}$ J. Kunnen, ${ }^{13}$ N. Kurahashi, ${ }^{27}$ T. Kuwabara, ${ }^{31}$ M. Labare, ${ }^{13}$ H. Landsman, ${ }^{27}$ M.J. Larson, ${ }^{36}$ M. Lesiak-Bzdak, ${ }^{35}$ M. Leuermann, ${ }^{1}$ J. Leute, ${ }^{30}$ J. Lünemann, ${ }^{28}$ J. Madsen, ${ }^{33}$ R. Maruyama, ${ }^{27}$ K. Mase, ${ }^{14}$ H.S. Matis, ${ }^{8}$ F. McNally, ${ }^{27}$ K. Meagher, ${ }^{16}$ M. Merck, ${ }^{27}$ P. Mészáros, ${ }^{37,}{ }^{38}$ T. Meures, $^{12}$ S. Miarecki, ${ }^{8,7}$ E. Middell, ${ }^{41}$ N. Milke, ${ }^{19}$ J. Miller, ${ }^{13}$ L. Mohrmann, ${ }^{41}$ T. Montaruli, ${ }^{21, c}$ R. Morse, ${ }^{27}$ R. Nahnhauer, ${ }^{41}$ U. Naumann, ${ }^{40}$ H. Niederhausen, ${ }^{35}$ S.C. Nowicki, ${ }^{20}$ D.R. Nygren, ${ }^{8}$ A. Obertacke, ${ }^{40}$ S. Odrowski, ${ }^{30}$ A. Olivas, ${ }^{16}$ M. Olivo, ${ }^{10}$ A. O'Murchadha, ${ }^{12}$ L. Paul, $^{1}$ J.A. Pepper, ${ }^{36}$ C. Pérez de los Heros, ${ }^{39}$ C. Pfendner, ${ }^{17}$ D. Pieloth, ${ }^{19}$ E. Pinat, ${ }^{12}$ N. Pirk, ${ }^{41}$ J. Posselt, ${ }^{40}$ P.B. Price, ${ }^{7}$ G.T. Przybylski, ${ }^{8}$ L. Rädel, ${ }^{1}$ M. Rameez, ${ }^{21}$ K. Rawlins, ${ }^{3}$ P. Redl, ${ }^{16}$ R. Reimann, ${ }^{1}$ E. Resconi, ${ }^{30}$ W. Rhode, ${ }^{19}$ M. Ribordy, ${ }^{24}$ M. Richman, ${ }^{16}$ B. Riedel, ${ }^{27}$ J.P. Rodrigues, ${ }^{27}$ C. Rott, ${ }^{17, d}$ T. Ruhe, ${ }^{19}$ B. Ruzybayev, ${ }^{31}$ D. Ryckbosch, ${ }^{22}$ S.M. Saba, ${ }^{10}$ T. Salameh, ${ }^{38}$ H.-G. Sander, ${ }^{28}$ M. Santander, ${ }^{27}$ S. Sarkar, ${ }^{32}$ K. Schatto, ${ }^{28}$ M. Scheel, ${ }^{1}$ F. Scheriau, ${ }^{19}$ T. Schmidt, ${ }^{16}$ M. Schmitz, ${ }^{19}$ S. Schoenen, ${ }^{1}$ S. Schöneberg, ${ }^{10}$ A. Schönwald, ${ }^{41}$ A. Schukraft, ${ }^{1}$ L. Schulte, ${ }^{11}$ O. Schulz, ${ }^{30}$ D. Seckel, ${ }^{31}$ Y. Sestayo, ${ }^{30}$ S. Seunarine, ${ }^{33}$ C. Sheremata, ${ }^{20}$ M.W.E. Smith, ${ }^{38}$ M. Soiron, ${ }^{1}$ D. Soldin, ${ }^{40}$ G.M. Spiczak, ${ }^{33}$ C. Spiering, ${ }^{41}$ M. Stamatikos, ${ }^{17, \text { e } T . ~ S t a n e v,}{ }^{31}$ A. Stasik, ${ }^{11}$ T. Stezelberger, ${ }^{8}$ R.G. Stokstad, ${ }^{8}$ A. StößI, ${ }^{41}$ E.A. Strahler, ${ }^{13}$ R. Ström, ${ }^{39}$ G.W. Sullivan, ${ }^{16}$ H. Taavola, ${ }^{39}$ I. Taboada, A. Tamburro, ${ }^{31}$ S. Ter-Antonyan, ${ }^{6}$ G. Tešić, ${ }^{38}$ S. Tilav, ${ }^{31}$ P.A. Toale, ${ }^{36}$ S. Toscano, ${ }^{27}$ D. Tosi, ${ }^{7}$ M. Usner, ${ }^{11}$ D. van der Drift, ${ }^{8,7}$ N. van Eijndhoven, ${ }^{13}$ A. Van Overloop, ${ }^{22}$ J. van Santen, ${ }^{27}$ M. Vehring, ${ }^{1}$ M. Voge, ${ }^{11}$ M. Vraeghe, ${ }^{22}$ C. Walck, ${ }^{34}$ T. Waldenmaier, ${ }^{9}$ M. Wallraff, ${ }^{1}$ R. Wasserman, ${ }^{38} \mathrm{Ch}$. Weaver, ${ }^{27} \mathrm{M}$. Wellons, ${ }^{27} \mathrm{C}$. Wendt, ${ }^{27}$ S. Westerhoff, ${ }^{27} \mathrm{~N}$. Whitehorn, ${ }^{27}$ K. Wiebe, ${ }^{28}$ C.H. Wiebusch, ${ }^{1}$ D.R. Williams, ${ }^{36}$ H. Wissing, ${ }^{16}$ M. Wolf, ${ }^{34}$ T.R. Wood, $^{20}$ K. Woschnagg, $^{7}$ C. Xu, ${ }^{31}$ D.L. Xu, ${ }^{36}$ X.W. Xu, ${ }^{6}$ J.P. Yanez, ${ }^{41}$ G. Yodh, ${ }^{23}$ S. Yoshida, ${ }^{14}$ P. Zarzhitsky, ${ }^{36}$ J. Ziemann, ${ }^{19}$ S. Zierke, ${ }^{1}$ A. Zilles, ${ }^{1}$ M. Zoll ${ }^{34}$

${ }^{1}$ III. Physikalisches Institut, RWTH Aachen University, Aachen, Germany

${ }^{2}$ School of Chemistry \& Physics, University of Adelaide, Adelaide, South Australia, Australia

${ }^{3}$ Department of Physics and Astronomy, University of Alaska Anchorage, Anchorage, AK, USA

${ }^{4}$ CTSPS, Clark Atlanta University, Atlanta, GA, USA

${ }^{5}$ School of Physics and Center for Relativistic Astrophysics, Georgia Institute of Technology, Atlanta, GA, USA

${ }^{6}$ Department of Physics, Southern University, Baton Rouge, LA, USA

${ }^{7}$ Department of Physics, University of California, Berkeley, CA, USA

${ }^{8}$ Lawrence Berkeley National Laboratory, Berkeley, CA, USA

${ }^{9}$ Institut für Physik, Humboldt-Universität zu Berlin, Berlin, Germany

${ }^{10}$ Fakultät für Physik und Astronomie, Ruhr-Universität Bochum, Bochum, Germany

${ }^{11}$ Physikalisches Institut, Universität Bonn, Bonn, Germany 
${ }^{12}$ Science Faculty CP230, Université Libre de Bruxelles, Brussels, Belgium

${ }^{13}$ Vrije Universiteit Brussel, Dienst ELEM, Brussels, Belgium

${ }^{14}$ Department of Physics, Chiba University, Chiba, Japan

${ }^{15}$ Department of Physics and Astronomy, University of Canterbury, Christchurch, New Zealand

${ }^{16}$ Department of Physics, University of Maryland, College Park, MD, USA

${ }^{17}$ Department of Physics and Center for Cosmology and Astro-Particle Physics, The Ohio State University,

Columbus, $\mathrm{OH}$, USA

${ }^{18}$ Department of Astronomy, The Ohio State University, Columbus, OH, USA

${ }^{19}$ Department of Physics, TU Dortmund University, Dortmund, Germany

${ }^{20}$ Department of Physics, University of Alberta, Edmonton, Alberta, Canada

${ }^{21}$ Département de physique nucléaire et corpusculaire, Université de Genève, Geneva, Switzerland

${ }^{22}$ Department of Physics and Astronomy, University of Gent, Gent, Belgium

${ }^{23}$ Department of Physics and Astronomy, University of California, Irvine, CA, USA

${ }^{24}$ Laboratory for High Energy Physics, École Polytechnique Fédérale, Lausanne, Switzerland

${ }^{25}$ Department of Physics and Astronomy, University of Kansas, Lawrence, KS, USA

${ }^{26}$ Department of Astronomy, University of Wisconsin, Madison, WI, USA

${ }^{27}$ Department of Physics and Wisconsin IceCube Particle Astrophysics Center, University of Wisconsin, Madison, WI, USA

${ }^{28}$ Institute of Physics, University of Mainz, Mainz, Germany

${ }^{29}$ Université de Mons, Mons, Belgium

${ }^{30}$ T.U. Munich, Garching, Germany

${ }^{31}$ Bartol Research Institute and Department of Physics and Astronomy, University of Delaware, Newark, DE, USA

${ }^{32}$ Department of Physics, University of Oxford, Oxford, UK

${ }^{33}$ Department of Physics, University of Wisconsin, River Falls, WI, USA

${ }^{34}$ Oskar Klein Centre and Department of Physics, Stockholm University, Stockholm, Sweden

${ }^{35}$ Department of Physics and Astronomy, Stony Brook University, Stony Brook, NY, USA

${ }^{36}$ Department of Physics and Astronomy, University of Alabama, Tuscaloosa, AL, USA

${ }^{37}$ Department of Astronomy and Astrophysics, Pennsylvania State University, University Park, PA, USA

${ }^{38}$ Department of Physics, Pennsylvania State University, University Park, PA, USA

${ }^{39}$ Department of Physics and Astronomy, Uppsala University, Uppsala, Sweden

${ }^{40}$ Department of Physics, University of Wuppertal, Wuppertal, Germany

${ }^{41}$ DESY, Zeuthen, Germany

a Physics Department, South Dakota School of Mines and Technology, Rapid City, SD, USA

${ }^{b}$ Los Alamos National Laboratory, Los Alamos, NM, USA

c also Sezione INFN, Dipartimento di Fisica, Bari, Italy

${ }^{d}$ Department of Physics, Sungkyunkwan University, Suwon, Republic of Korea

eNASA Goddard Space Flight Center, Greenbelt, MD, USA

MS received 8 April 2013 and accepted in revised form 2 September 2013 